\title{
Taktik Bertahan Pemuda Minonitas: Perlawanan Diam dan Mimikri Pemuda Aboge di Lembaga Pendidikan
}

\author{
Mochammad Zaka Ardiansyah ${ }^{\text {a) }}$
}

a) Institut Agama Islam Negeri Jember

\section{ABSTRAK}

Artikel ini mengungkap bahwa dalam merespons diskriminasi beragama yang menimpanya selama belajar di lembaga pendidikan, pemuda Aboge tak menerimanya dengan pasrah. Alih-alih diam dan menerima menjadi sasaran labeling heresy di lembaga pendidikan, pemuda Aboge mengembangkan beragam survival tactics dan meresponsnya dengan melakukan mimikri dan perlawanan diam. Bentuknya, pertama, melakukan mimikri dalam multiple identity, antara NU dan Aboge. Kedua, berpura-pura sedang menstruasi sebagai bentuk kamuflase di pesantren namun diam-diam salat dan baru memulai puasa Ramadan ala Aboge keesokan harinya. Ketiga, berpura-pura melakukan ibadah sunah untuk mengesankan keesokan harinya dirinya telah mulai "puasa wajib" Ramadan bersama mayoritas. Artikel ini adalah hasil penelitian kualitatif dengan teknik wawancara mendalam yang menempatkan mimikri Homi K. Bhabha dan perlawanan diam James C. Scott sebagai teori, dan pos kolonial sebagai pendekatan. Hasil studi ini mengungkap bahwa meski salah seorang pemuda Aboge belajar di tengah lanskap komunitas ordinat kampus Muhammadiyah, ia tak menjadi obyek subordinat. Mereka melakukan kamuflase dengan mimikri menggunakan identitas ordinat Muhammadiyah serta memanfaatkan in-between space untuk dapat survive. Nampaknya, pemuda Aboge justru menciptakan ruang baru dengan mengkonstruksi identitas lain secara artifisial, yakni mimikri dengan identitas NU sebagai taktik bertahan. Kertas kerja ini menghasilkan sebuah implikasi penting dalam studi poskolonial, yakni ruang ketiga yang berbeda dengan in-between space yang ditawarkan Homi K. Bhabha. Ruang ketiga yang diciptakan pemuda Aboge adalah ruang identitas baru yang tak mengadopsi identitas kultural penjajah dan terjajah, karena pemuda Aboge meminjam identitas NU untuk melakukan mimikri saat menghadapi sang ordinat.

\section{ABSTRACT}

This article reveals that in responding to the religious discrimination against them while studying at educational institutions, Aboge youths fight back. Instead of being silent and accepting of being the target of heresy labeling in schools, madrasas, campuses, and pesantren, Aboge youths develop various survival tactics and respond to the issues by engaging in mimicry and silent resistance. First, they perform mimicry in multiple identities, between NU and Aboge. Second, they pretend that they are menstruating to camouflage at pesantren but then secretly praying and starting the Aboge-style Ramadan fast on the next day. Third, they preten to do Sunnah worship to impress the next day they start the "obligatory fast" of Ramadan together with the majority. This paper is based upon a qualitative study employing in-depth interview and places the mimicry of Homi K. Bhabha and James C. Scott's silent resistance as theory, and the post-colonial as an approach. The results of this study founds that young Aboge who studied in the midst of the Muhammadiyah campus, they apparently are not becoming subordinate. They carried out mimicry by taking Muhammadiyah as the ordinate identity and utilizing the in-between space to survive. Apparently, the ordinate created a new space by constructing artificial identity towards the Aboge by defining them as NU community. This working paper produces an important finding in post-colonial studies, namely a third space that is different from the in-between space offered by Homi K. Bhabha. This third space is a new identity space that does not adopt identities of the colonizer nor the colonized, because the Aboge borrowed NU identity to perform mimicry when facing the ordinate.
KATA KUNCI

Pendidikan; Muslim

Minoritas; Aboge; Taktik

Bertahan; Bid'ah.

\section{KEYWORDS}

Education; Minority Muslim; Aboge; Survival Tactics; Heresy. 


\section{A. Prawacana}

Orang Aboge ${ }^{1}$ adalah komunitas Muslim yang meyakini dan menggunakan metode perhitungan kalender Aboge $^{2}$ untuk menghitung jatuhnya Hari Raya dan hari pelaksanaan aktivitas lain. ${ }^{3}$ Komunitas ini mengamalkan ajaran Ahl Sunnah wa al-Jamä'ah ${ }^{4}$ dan pada umumnya menjalankan tarekat, baik tarekat Naqshabandiyyah, ${ }^{5}$ Naqshabandiyyah Khālidiyyah Mujaddadiyyah Al 'Alkyah, ${ }^{6}$ Tijāniyyah, $^{7}$ maupun Shattāriyyah. ${ }^{8}$ Aboge sendiri adalah akronim dari Alip Rebo Wage. ${ }^{9}$

Sebagai derivasi area studi Islam Jawa, studi-studi terhadap Aboge sebagai sistem numerasi dan sebagai komunitas yang telah dilakukan oleh para peneliti selama ini lebih fokus pada asimilasi Islam dan budaya Jawa yang dipraktikkan komunitas Aboge, ${ }^{10}$ strategi adaptasi komunitas Aboge, ${ }^{11}$ sistem kalender Aboge, ${ }^{12}$ tata ruang pemukiman komunitas Aboge, ${ }^{13}$ etnomatematika Aboge, ${ }^{14}$ dan model

\footnotetext{
${ }^{1}$ Masyarakat Tapal Kuda beretnis Madura menyebutnya dengan Reng Abugih sementara masyarakat beretnis Jawa menyebutnya Wong Aboge. Keduanya bermakna orang Aboge.

${ }^{2}$ Harsun, Wawancara dengan Kiai Harsun, seorang Tokoh Aboge di Desa Karangsari, Kecamatan Rowosari, Lumajang, 16 November 2017.

${ }^{3}$ Clifford Geertz, The Religion of Java (Chicago: The University of Chicago Press, 1976), 380.

${ }^{4}$ Ahmad Syaukani, Wawancara dengan Kiai Ahmad Syaukani, seorang Tokoh Aboge di Desa Podang, Kecamatan Karang Lo, Probolinggo, Agustus 2016.
}

${ }^{5}$ Harsun, Wawancara dengan Kiai Harsun, seorang Tokoh Aboge di Desa Karangsari, Kecamatan Rowosari, Lumajang.

${ }^{6}$ Komunitas Aboge Dusun Kertas (nama samaran) adalah penerus sanad Tarekat Kiai Usman Gedang (Gedang adalah dusun di timur dusun Tambakberas yang kini berada di kawasan pesantren Tambak Beras Jombang, nama dusun Gedang kerap dinisbahkan pada Kiai Usman, termasuk oleh Bruinessen) yang menjadi kunci penting jejaring tarekat Naqshabandiyyah di Jawa Timur. Pasca Wafatnya Kiai Usman, jamaah tarekat ini kemudian dipindah dari Dusun Gedang ke Dusun Kertas yang berjarak 3,5 kilometer Timur Laut Gedang dan dipimpin oleh menantunya, Kiai Abdullah. Selengkapnya diungkap Bruinessen dan Kiai Nasiri dalam sesi wawancara dengan penulis. Martin van Bruinessen, Tarekat Naqsyabandiyah di Indonesia (Bandung: Mizan, 1992), 168; Nasiri, Wawancara dengan Kiai Nasiri, seorang Tokoh Aboge Dusun Kertas, Desa Dolo, Kecamatan Puntodewo, Jombang, 25 November 2017; Penyerahan tongkat estafet tarekat dan Kiai Usman Gedang ke Kiai Abdullah dan perpindahan lokasi kegiatan tarekat dari Gedang ke Dusun Kertas (nama samaran) dapat juga dibaca dalam Safrizal Rambe, Peletak Dasar Tradisi Berpolitik NU Sang Penggerak Nahdlatul Ulama KH. Abdul Wahab Chasbullah Sebuah Biografi (Jakarta: Madani Institute, 2020), 22.

${ }^{7}$ Syaukani, Wawancara dengan Kiai Ahmad Syaukani, seorang Tokoh Aboge di Desa Podang, Kecamatan Karang Lo, Probolinggo.

${ }^{8}$ Sakirman, “Islam Aboge dalam Tradisi Jawa Alastua," Ibda': Jurnal Kebudayaan Islam 14, no. 2 (Juli 2016 ): 176.

${ }^{9}$ Aboge bermakna tanggal 1 Muharram pada tahun Alip, akan jatuh pada hari Rabu Wage. Siklus Aboge adalah 8 tahun atau satu Windu. Keyakinan atas metode perhitungan almanak ini menyebabkan pelaksanaan puasa Ramadan dan hari raya kaum Muslim Aboge kerap berbeda dengan pemerintah dan kelompok muslim arus utama lain. Selengkapnya baca Abdurrahman Misno Bambang Prawiro, "Islam Aboge: Islam and Cultural Java Dialogue (A Study of Islam Aboge Communities in Ujungmanik, Cilacap, Central Java, Indonesia)," International Journal of Nusantara Islam 1, no. 2 (2013): 102; Baca juga Sakirman, “Islam Aboge dalam Tradisi Jawa Alastua," 174.

${ }^{10}$ Prawiro, "Islam Aboge: Islam and Cultural Java Dialogue (A Study of Islam Aboge Communities in Ujungmanik, Cilacap, Central Java, Indonesia)," 102-3.

${ }^{11}$ Sulaiman, "Islam Aboge; Pelestarian Nilai-nilai Lama di Tengah Perubahan Sosial," Analisa: Journal of Social Science and Religion 20, no. 1 (2013): 1-12.

${ }^{12}$ Arnis Rachmadhani, "Role of Wali, Ancient Mosque and Sacred Tomb in Islam Spreading Dynamics in Cikakak," IBDA': Jurnal Kajian Islam dan Budaya Vol. 14, No. 2 (Desember 2016): 227-28.

${ }^{13}$ Wita Widyandini, Yohana Nursruwening, dan Basuki, “Penerapan Konsep Dasar Pemukiman Aboge Cikakak pada Pemukiman Aboge Cibangkong di Kabupaten Banyumas" (SENATEK 2015 Fakultas Teknik, Purwokerto: Universitas Muhammadiyah Purwokerto, 2015), 7-13.

${ }^{14}$ Muhammad Alfi Syahrin, Turmudi, dan Entit Puspita, "Study Ethnomathematics of Aboge (Alif, Rebo, Wage) Calendar as Determinant of the Great Days of Islam and Traditional Ceremony in Cirebon Kasepuhan Palace," dalam Proceedings of International Seminar on Mathematics, Science, and Computer Science Education (MSCEIS 2015) (International 
matematika sistem kalender Aboge. ${ }^{15}$ Sementara, studi terhadap pemuda Aboge masih terbatas pada praktik pengalaman beragama pemuda Aboge di lembaga pendidikan dan kekerasan simbolik yang menimpa mereka. ${ }^{16}$ Studi terhadap pemuda Aboge masih cukup minim, sehingga dirasa penting melakukan studi terhadap taktik bertahan pemuda Aboge di lembaga pendidikan merespons berbagai bentuk tindak diskriminatif yang dirasakan pemuda Aboge sebagai kelanjutan dari artikel yang disebut terakhir.

Artikel ini secara khusus dibuat untuk mengungkap ragam taktik bertahan tiga orang pemuda Aboge menghadapi berbagai keadaan yang tidak menguntungkannya di lembaga pendidikan, khususnya kekhawatiran mendapatkan tindak diskriminatif dan praktik diskriminatif yang menimpanya di lembaga pendidikan, baik sekolah, kampus keagamaan, maupun pesantren di Kabupaten Probolinggo dan Lumajang, Jawa Timur, Indonesia. Paper ini menyajikan bentuk-bentuk survival tactics pemuda Aboge saat mereka belajar di lembaga pendidikan di lembaga pendidikan, saat penelitian ini berlangsung maupun beberapa tahun sebelumnya saat para pemuda Aboge melakukannya. ${ }^{17}$

Setelah mendiskusikan data lapangan dengan teori poskolonial Homi K. Bhabha yang memfokuskan pada mimikri identitas terjajah dalam merespons penjajah dan teori perlawanan diam James C. Scott, kertas kerja ini mengungkap pertama pemuda Aboge yang kuliah di kampus Muhammadiyah mengganti identitas secara dinamis, antara NU dan Aboge sebagai taktik bertahan, kedua penyamaran santri Aboge di pesantren dengan cara berpura-pura "menstruasi" namun diamdiam salat, dan ketiga pemuda Aboge berpura-pura mengikuti ibadah sunah di sekolah agar mengesankan bahwa keesokan harinya dirinya telah memulai berpuasa bersama pemerintah, dan mengaburkan realitas bahwa dirinya akan berpuasa bersama Aboge dua hari kemudian.

Kertas kerja ini memosisikan hasil wawancara mendalam dengan para pemuda Aboge, tokoh Aboge, dan tokoh Islam tradisional di kawasan komunitas Aboge di Kabupaten Probolinggo dan Lumajang pada 2018 sebagai data utama dan didukung data wawancara yang penulis dapatkan pada 2017 dan 2016. Karena beberapa data utama dari kertas kerja ini adalah bagian dari program bantuan penelitian BOPTN kampus tempat penulis mengabdi, atas masukan reviewer penelitian, seluruh identitas informan dan desa tempat tinggal para informan dalam naskah ini disamarkan oleh penulis demi keamanan informan.

Seminar on Mathematics, Science, and Computer Science Education (MSCEIS 2015), AIP Publishing, 2016), 060009-1060009-10.

${ }^{15}$ A. Prabowo dkk., "Carrying Javanese Local Wisdom in Mathematical Model," Journal of Physics: Conference Series 1179 (Juli 2019): 1-6.

${ }^{16}$ Mochammad Zaka Ardiansyah, "School, Symbolic Violence, and Religious Experience of Aboge Youth," Didaktika Religia Vol. 8, No. 1 (2020): 51-77.

${ }^{17}$ Beberapa tindak diskriminatif, khususnya yang menimpa pemuda Aboge di lembaga pendidikan dapat dibaca di Ardiansyah, "School, Symbolic Violence, and Religious Experience of Aboge Youth." 


\section{B. Komunitas Aboge di Tapal Kuda}

Dalam lanskap kehidupan sosial masyarakat beretnis Madura yang tinggal di kawasan geopolitik Tapal Kuda, ${ }^{18}$ kaum Muslim Aboge merupakan komunitas Muslim periferal yang meyakini dan melestarikan sistem perhitungan kalender Aboge yang diasosiasikan dengan kalender Jawa-Islam. Dalam perspektif Redfield adalah kaum Muslim Aboge adalah representasi komunitas yang setia menjalankan little tradition, sementara jamiyah Nahdlatul Ulama (NU), komunitas yang mengitari komunitas Aboge, merupakan representasi komunitas arus utama yang menjaga great tradition ${ }^{19}$ berkat otoritas keilmuan pesantren yang dipegangnya, khususnya oleh para elite terpelajar.

Keyakinan atas perhitungan Aboge dan ramalan Primbon dan Mujarabat hidup dan terpelihara dalam derap langkah kaum Muslim Aboge, sebagai penjaga little tradition, di tengah masyarakat di beberapa desa pinggiran di kawasan Tapal Kuda ${ }^{20}$ yang kerap diklasifikasikan usang oleh sebagian komunitas Muslim tradisional terdidik.

Di Tapal Kuda, sebaran kaum Muslim Aboge teridentifikasi di beberapa Kecamatan di Probolinggo seperti Kecamatan Karang Lo, yang terletak 14 kilometer arah Selatan Alun-alun Probolinggo dan Kecamatan Budi Joyo, 16 kilometer dari titik yang sama, beberapa Kecamatan di Lumajang seperti Kecamatan Umpak Palu, 21 kilometer arah Selatan dari Alun-alun Lumajang,

\footnotetext{
${ }^{18}$ Kawasan Tapal Kuda dipahami berbeda oleh para peneliti. Wibisono dan Haryono mengungkap bahwa kawasan tapal kuda membentang dari Banyuwangi kawasan Timur, kawasan Selatan Jember, Bondowoso, Kawasan Utara Situbondo Situbondo, Probolinggo, kawasan Barat Lumajang, dan Pasuruan yang diidentikkan dengan area kebudayaan Pandalungan. Sementara dari perspektif geoekonomi, Supriono sebagaimana disitir Soejono, dkk. menyatakan bahwa kawasan ini membentang dari Sumenep hingga Situbondo dan membaginya menjadi kawasan pertumbuhan ekonomi (growth area) yang terdiri dari Surabaya dan Sidoarjo, dan sub-area yang mencakup empat Kabupaten di pulau Madura, Pasuruan, Probolinggo, dan Situbondo. Dalam naskah ini, penulis menggunakan cakupan Tapal Kuda pertama. Perbandingan lengkap dapat dibaca dalam Bambang Wibisono dan Akhmad Haryono, Komunikasi Antar Budaya di Tapal Kuda: Antisipasi Konflik dalam Keluarga (Yogyakarta: Deepublish, 2020), 13-14; Djoko Soejono, Agus Supriono, dan Julian Adam Ridjal, "Faktor Pendorong dan Penghambat Mewujudkan Model Sinergis Pengembangan Wilayah Tapal Kuda menjadi Kesatuan Daerah Perencanaan di Era Otonomi Daerah," JSEP (Journal of Social and Agricultural Economics) Vol. 5, No. 1 (2011): 24.

${ }^{19}$ Great tradition disejajarkan Redfield dengan high culture, sementara little tradition setara dengan low culture. Robert Redfield, Peasant Society and Culture: An Anthropological Approach to Civilization (Chicago: The University of Chicago Press, 1956), 70.

${ }^{20}$ Primbon dan Mujarabat menurut Bruinessen adalah derivasi dari kitab Shams al-Ma'arif karya al-Buni. Mujarabat menurutnya adalah ringkasan dari Shams al-Ma'arif, sementara Primbon memiliki konten yang lebih variatif. Martin van Bruinessen, "Global and Local in Indonesian Islam," Southeast Asian Studies Vol. 37, No. 2 (September 1999); Pada wawancara pertama di tahun 2016, Kiai Muamar mengungkap bahwa Primbon serupa dengan Mujarabat. Muamar, Wawancara dengan Kiai Muamar, seorang tokoh Aboge Desa Karang Lo, Kecamatan Karang, Probolinggo, Agustus 2016; Dalam wawancara kedua pada 2018, Kiai Muamar mengungkap bahwa Kitab Mujarabat bersumber dari Alquran dan Hadis. Muamar, Wawancara dengan Kiai Muamar, seorang tokoh Aboge Desa Karang Lo, Kecamatan Karang, Probolinggo, 23 Januari 2018; Syaukani, tokoh Aboge Desa Podang, menyatakan dalam melakukan perhitungan ramalan, ia merujuk pada Primbon berbahasa Jawa, Indonesia, dan Arab yang sebagian didapatkannya dari Kakek dari jalur Ayah dan Ibu yang sama-sama paranormal. Kitab Primbon digunakannya untuk meramal nasib dan melakukan perhitungan hari bagi setiap orang yang minta bantuan padanya. Syaukani juga meramal kehidupan dan jodoh penulis. Syaukani, Wawancara dengan Kiai Ahmad Syaukani, seorang Tokoh Aboge di Desa Podang, Kecamatan Karang Lo, Probolinggo.
} 
Kecamatan Rowosari, 20-an kilometer arah Timur Laut dari titik yang sama, dan Kecamatan Sari Rejo, 25-an kilometer arah Utara dari lokasi serupa.

Di Banyuwangi, komunitas ini masih lestari di beberapa kawasan seperti di Kecamatan Klitikan, 60-an kilometer arah Barat Daya Kota Banyuwangi dan Kecamatan Sisik, 40-an kilometer arah Barat Kota Banyuwangi. Sementara di Jember, komunitas ini eksis di Kecamatan Kaca Belah, 50-an kilometer Barat Daya Kota Jember dan Kecamatan Sirep Mas, 10-an kilometer Timur titik yang sama. Para Pemuda Aboge yang menjadi informan penelitian ini berasal dari Kecamatan Karang Lo, Probolinggo dan Kecamatan Umpak Palu, Lumajang.

Sebagai representasi dari kelompok yang memegang legitimasi kebenaran melalui instrumen telaah kitab kuning di pesantren serta melakukan reproduksi-reaktualisasi hukum Islam melalui forumforum bahthul masait, elite NU memegang otoritas kuasa di tingkat desa di kawasan Tapal Kuda. Organisasi ini di desa menjaga great tradition-nya dengan mengajarkan standar kebenaran ajarannya melalui lembaga pendidikan madrasah dan pesantren secara masif dan sistematis, sementara komunitas Aboge berjalan secara kultural tanpa lembaga pendidikan, hanya diajarkan dari orang tua kepada anak dengan memanfaatkan hegemoni pasif kiai Aboge dan nenek moyangnya.

Di beberapa desa di kawasan geokultural Tapal Kuda, kaum Muslim Aboge, mendapat label heresy dari elite Islam arus utama dalam bentuk pertama label sebagai kelompok sesat dan menyesatkan yang dialamatkan pada kaum Muslim Aboge karena keyakinannya pada sistem ramalan berbasis Primbon dan Mujarabat, ${ }^{21}$ dan label kedua, puasa hari terakhir yang dilaksanakan kaum Muslim Aboge tatkala pemerintah telah menetapkan bahwa hari itu telah Idul Fitri tidak boleh dilakukan, haram, tak berpahala, dan berdosa, ${ }^{22}$ yang dialamatkan pada pelaksanaan puasa komunitas Aboge. Kedua label ini dilekatkan oleh dua orang tokoh pendidikan di kawasan komunitas Aboge. Ketiga, komunitas Aboge dilabeli meyakini "agama Aboge" yang dinilai tak relevan dengan tradisi beribadah masyarakat Muslim arus utama, sehingga pemuda desa perlu turun tangan untuk mengubahnya. ${ }^{23}$

Hingga kini, kawasan ini, keyakinan atas perhitungan Aboge menjadi bagian dari derap keseharian sebagian masyarakat yang meyakini secara turun-temurun bahwa sistem perhitungan kalender Aboge masih relevan, meski kontras dengan sistem perhitungan kalender yang digunakan pemerintah dan pengikut komunitas arus utama di kawasan ini, NU. Jika awal puasa Ramadan dan Idul Fitri selayaknya menjadi momentum membahagiakan bagi umat Muslim, namun tak berlaku bagi

\footnotetext{
${ }^{21}$ Bustanul Arif, Wawancara dengan Kiai Bustanul Arif, Desa Kombong, Kecamatan Budi Joyo, Probolinggo, 23 Januari 2018; Sementara Bindereh Zul, pimpinan komunitas Aboge Desa Bendo, memaparkan pernah dituduh sesat oleh tokoh agama kecamatan Budi Joyo. Zulfikar, Wawancara dengan Bindereh Zul, seorang Tokoh Aboge Desa Bendo, Kecamatan Budi Joyo, Pobolinggo, Desember 2018.

${ }^{22}$ Ardiansyah, "School, Symbolic Violence, and Religious Experience of Aboge Youth," 70.

${ }^{23}$ Dari catatan kaki diketahui bahwa informasi ini diungkap oleh Sulistio, Kepala Dusun (Kamituwo) Desa Blukar, Kecamatan Sisik, Banyuwangi yang menjadi lokasi tinggal komunitas Aboge. Identitas informan dan lokasi disamarkan oleh penulis paper. Ibid., 55.
} 
Mochammad Zaka Ardiansyah

komunitas Aboge. Kekhusyukan ibadahnya tak jarang terganggu dengan kedatangan pewarta media yang meliput praktik ibadah yang kerap membuat privasi ibadah komunitas Aboge terganggu. Sorotan media atas perbedaan waktu pelaksanaan Salat Id yang dilakukan komunitas ini menjadikan pengikut Aboge risi. ${ }^{24}$

\section{Rekognisi Minoritas Muslim di Lembaga Pendidikan}

Rekognisi atas minoritas keagamaan masih menjadi barang mahal dan pekerjaan rumah yang tak kunjung selesai di Indonesia. ${ }^{25}$ Pada beberapa kelompok minoritas agama, hak beragama dan berkeyakinan sebagai warga negara masih kerap menjadi barang mahal untuk dinikmati. ${ }^{26}$ Wajar saja, dengan tak didapatkannya rekognisi atas keyakinan yang diyakini minoritas, menjadikan kelompok ini rentan tak mendapatkan layanan publik yang disediakan negara untuk segenap warganya, termasuk layanan pendidikan non-diskriminatif.

Di sisi lain, beragama, meyakini kepercayaan, serta memilih pendidikan dan pengajaran adalah hak asasi setiap manusia yang dilindungi konstitusi. ${ }^{27}$ Pun bagi peserta didik yang masih masuk dalam kategori anak, hingga usia 18 tahun, negara berkewajiban memberikan perlindungan khusus atas pemenuhan hak anak dari kelompok minoritas, termasuk pendidikan. ${ }^{28}$

Tak itu saja, negara sesungguhnya telah menjamin setiap warga negara mendapatkan layanan pendidikan agama yang sesuai dengan agamanya dan diajar oleh pendidik yang relevan dengan agamanya yang tergambar jelas dari Pasal 12 Ayat (1) butir a Undang-undang Nomor 20 tentang Sistem Pendidikan Nasional, ${ }^{29}$ sehingga setiap sekolah, madrasah, maupun satuan pendidikan non-formal seperti PKBM dan SKB, baik negeri dan swasta harus memberikan layanan pendidikan yang disesuaikan dengan agama sang peserta didik. Meski demikian, negara belum memiliki instrumen penyelenggaraan pendidikan agama bagi kelompok minoritas agama, sehingga praktik intoleransi dan diskriminasi masih jamak terjadi pada mereka.

\footnotetext{
${ }^{24}$ Fauzi Amin, Wawancara dengan Fauzi Amin, seorang pemuda Aboge dari Desa Kendang Kempul, Kecamatan Karang Lo, Probolinggo, Desember 2018.

${ }^{25}$ Berdasarkan pantauan Wahid Foundation, pelanggaran kebebasan beragama terjadi 184 kali peristiwa dengan 215 tindakan pelanggaran. Angka ini turun dalam 2 tahun berturut-turut jika dibandingkan dengan hasil pantauan lembaga yang sama pada 2018 dan 2017. Yenny Zannuba Wahid dkk., "Laporan Tahunan Kemerdekaan Beragama/Berkeyakinan (KBB) Tahun 2019 di Indonesia: Kemajuan Tanpa Penyelesaian Akar Masalah" (Jakarta: Wahid Foundation, 2020), 35.

${ }^{26}$ Prasangka yang melekat dalam benak publik berimbas pada kekerasan yang menimpa siswa SMA Piri karena sang korban bersekolah di sekolah sekolah yang berafiliasi pada Ahmadiyah, yang difatwakan sesat oleh MUI. Anis Farikhatin, "Berhadapan dengan Prasangka: Merespons Isu Sesat Ahmadiyah terhadap Sekolah PIRI I Yogyakarta," dalam Mengelola Keragaman di Sekolah: Gagasan dan Pengalaman Guru, ed. oleh Suhadi dkk. (Yogyakarta: CRCS, 2016), 1-16.

${ }^{27}$ Undang-undang Dasar Negara Republik Indonesia Tahun 1945 (1945) Pasal 28E Ayat (1) dan (2).

${ }^{28}$ Undang-undang Republik Indonesia Nomor 35 Tahun 2014 tentang Perubahan atas Undang-undang Nomor 23 Tahun 2002 tentang Perlindungan Anak (2014) Pasal 9 Ayat (1), Pasal 21 Ayat (1), dan Pasal 59 Ayat (2) Butir c.

${ }^{29}$ Sekretariat Negara RI, Undang-undang Nomor 20 Tahun 2003 tentang Sistem Pendidikan Nasional, (2003) Pasal 12 Ayat (1) butir a.
} 
Wajah intoleransi terhadap kelompok minoritas Muslim di lembaga pendidikan tercermin dalam survei yang dihelat Convey dan PPIM tahun 2018. Dalam survei yang membidik wajah keagamaan siswa dan mahasiswa ini menemukan bahwa $86,55 \%$ responden setuju jika pemerintah mengambil tindakan tegas dengan melarang eksistensi kelompok minoritas yang dinilai menyimpang. ${ }^{30}$

Bagi pelaku agama-agama leluhur (indigenous religions), persoalan pengakuan terhadap identitas keagamaannya tak hanya berimbas pada pemenuhan hak beragama di sekolah, namun juga identitas kewargaan dalam KTP dan Kartu Keluarga dan pengesahan administratif semisal KTP dan Akta Kelahiran yang berimbas pada tidak terpenuhinya berbagai layanan publik lain yang menjadi hak setiap warga negara seperti kesehatan, dan pekerjaan. ${ }^{31}$

\section{Aboge, Metode Perhitungan Kalender Islam Jawa: Ditinggalkan, namun Dipertahankan}

Pemuda Aboge tumbuh besar dalam tradisi dan keyakinan beragama komunitas Muslim Aboge. Dalam tradisi Islam Jawa, Aboge pada dipahami pengikutnya sebagai "sistem" perhitungan kalender untuk menentukan awal bulan lunar Hijriyah, ${ }^{32}$ namun kini kerap diidentikkan dengan "komunitas" yang masih bertahan untuk mengikuti metode Aboge. Komunitas -yang kemudian dikenal dengan orang Aboge- ini kini kerap dipersepsikan kuno dan keras kepala karena tak mau beradaptasi dengan sistem perhitungan Hijriyah yang digunakan oleh Kementerian Agama, bahkan dilabeli Kejawen. ${ }^{33}$

Sebagai sistem perhitungan kalender, Aboge, memahami bahwa perhitungan bulan Hijriyah melibatkan 3 domain, yakni tahun, hari, dan hari pasar dalam tradisi Jawa. Aboge adalah akronim dari kata "Alip, Rebo, Wage". Sistem perhitungan Aboge menggunakan perpaduan Alip, satu di antara delapan tahun dalam 1 windu, Rebo, satu hari dalam seminggu, dan Wage, satu dari lima hari pasaran Jawa. ${ }^{34}$ Masyarakat Islam Jawa, secara turun-temurun menggunakan Aboge sebagai basis numerasi dan penentuan awal bulan Hijriyah, termasuk dalam pantauan Clifford Geertz tatkala melakukan studi etnografi di Mojokutho dalam kurun 1957-1959. Pada tahun tersebut, di Mojokutho, komunitas abangan dan priayi merayakan Idul Fitri (Riyaya) merujuk pada metode Aboge. ${ }^{35}$

\footnotetext{
${ }^{30} \mathrm{Tim}$ PPIM UIN Syarif Hidayatullah Jakarta, Api dalam Sekam: Keberagamaan Muslim Gen-Z: Survei Nasional tentang Keberagamaan di Sekolah dan Universitas di Indonesia (Tangerang Selatan: PPIM UIN Jakarta dan UNDP Indonesia, 2018), 11.

${ }^{31}$ Zainal Abidin Bagir dan Samsul Maarif, "Pengantar," dalam Pasang Surut Rekognisi Agama Leluhur dalam Politik Agama di Indonesia (Yogyakarta: CRCS, 2018), iii-vii.

${ }^{32}$ Kiai Nasiri dan Kiai Harsun juga mengungkap bahwa Aboge adalah sistem perhitungan kalender. Nasiri, Wawancara dengan Kiai Nasiri, seorang Tokoh Aboge Dusun Kertas, Desa Dolo, Kecamatan Puntodewo, Jombang; Harsun, Wawancara dengan Kiai Harsun, seorang Tokoh Aboge di Desa Karangsari, Kecamatan Rowosari, Lumajang.

${ }^{33}$ Sumanto Al Qurtuby, "Reconciliation from Below: Indonesia's Religious Conflict and Grassroots Agency for Peace," Peace Research Vol. 44/45, No. 2/1 (2012/2013): 150 dan 161.

${ }^{34}$ Contoh pemanfaatan sistem Aboge untuk penentuan hari pelaksanaan Idul Fitri dapat dilihat di Geertz, The Religion of Java, 380; Sistem perhitungan Aboge yang lebih lengkap dapat dibaca di Prawiro, "Islam Aboge: Islam and Cultural Java Dialogue (A Study of Islam Aboge Communities in Ujungmanik, Cilacap, Central Java, Indonesia)," 106.

${ }^{35}$ Geertz, The Religion of Java, 380.
} 
Mochammad Zaka Ardiansyah

Meski Aboge merupakan sistem kalender Islam Jawa, namun sistem ini juga digunakan oleh komunitas masyarakat Madura yang tinggal di beberapa wilayah di Tapal Kuda yang sistem numerologinya merujuk pada Mujarabat dan Primbon. Di Tapal Kuda, komunitas Aboge kini menjadi minoritas, dan di sebagian dapat berasimilasi dan hidup harmoni dengan komunitas mayoritas, NU. Meski demikian, di beberapa kawasan lain terjadi disharmoni antar-keduanya, termasuk yang dampaknya secara tak langsung dirasakan pemuda Aboge di lembaga pendidikan. ${ }^{36}$

\section{E. Mimikri dan Resistensi Minoritas Subordinat}

Dalam paradigma poskolonial Homi K. Bhabha, posisi dominan penjajah sebagai pihak ordinat dan posisi terjajah sebagai pihak subordinat tidak lagi relevan. Berkat migrasi dengan berbagai variannya, komposisi demografi masyarakat tak lagi bisa dengan mudah diidentifikasi sebagai budaya nasional yang homogen berhadapan dengan budaya pendatang. Pertukaran dan komunikasi antarbudaya menjadikan subordinat mendefinisikan ulang identitasnya dan mengaburkan batas budaya yang dikonstruksi penjajah yang selama ini seolah final. ${ }^{37}$

Pembagian kelas sosial secara biner menjadi ordinat-subordinat sebagai subject position yang mempertahankan stereotip penjajah sebagai ordinat dan terjajah sebagai subordinat dalam studi poskolonial tak lagi memadai untuk mendefinisikan identitas individu terjajah yang terjebak di tengah pertempuran kuasa yang menempatkannya kerap berinteraksi --untuk tidak mengatakan tergantung-dengan penjajah namun diam-diam meneguhkan identitasnya yang otonom. Misal, subyek minoritas yang belajar atau bekerja pada institusi yang dikelola subyek mayoritas mendefinisikan identitas baru di tengah ruang "antara" penjajah-terjajah (in-between space), yakni ruang retakan yang dimanfaatkan oleh subyek minoritas untuk mendefinisikan ulang identitasnya dengan "berkolaborasi" sekaligus terus "berkontestasi" dengan sang dominan. "Rekahan" ini adalah arena baru terjadinya negosiasi, kolaborasi, sekaligus kontestasi intersubyektif-kolektif yang menjadikan rasa nasionalisme, kesamaan sejarah masa lalu, dan nilai kultural menjadi alasan yang kuat bagi subordinat untuk mempertahankan identitas aslinya di tengah mengenakan identitas baru, "sebagai dominan." Dalam "ruang antara" yang sebelumnya diabaikan pegiat poskolonial ini, Bhabha fokus mendefinisikan bagaimana subordinat membentuk in-between space dalam memaparkan strategi penyamaran yang dipilih dan direpresentasikan subordinat dengan sangat konfliktual-antagonistik, meski tak jarang juga berwajah kolaboratif-dialogis. ${ }^{38}$

Menurut Bhabha, dalam setting lokasi di pinggiran sekat budaya (liminal space), subordinat mendapatkan kesempatan --untuk tidak mengatakan tuntutan-- untuk mengadopsi budaya dominan

\footnotetext{
${ }^{36}$ Ardiansyah, "School, Symbolic Violence, and Religious Experience of Aboge Youth," 51-77.

${ }^{37}$ Homi K. Bhabha, The Location of Culture (London: Routledge, 1994), 5.

${ }^{38}$ Bhabha, The Location of Culture, 1-2.
} 
sambil diam-diam memperjuangkan identitasnya dengan melakukan kamuflase dengan mimikri. ${ }^{39}$ Sebagai bentuk kamuflase, mimikri mempertahankan ambivalensi karena meniru banyak format budaya dominan, namun diam-diam mempertahankan identitas aslinya sambil mengolok-olok (mockery). Mimikri yang dilakukan subordinat mengambil bentuk kompromi yang ironis, karena ia meniru dan mereplikasi identitas dominan -bukan merepresentasikannya- namun memosisikan diri berbeda. Dalam menjalankan mimikri, pihak lemah harus mendayagunakan potensinya agar selalu licik dan licin sehingga membingungkan sang dominan. ${ }^{40}$

Mimikri tentunya berhasil membuat bangunan kuasa wacana yang dibangun penjajah terhadap terjajah menjadi kacau balau karena sekat keduanya dikacaukan oleh ruang baru yang dibuat oleh subordinat dengan mendefinisikan ulang identitasnya. Ruang baru ini mengadopsi identitas penjajah sekaligus diam-diam mempertahankan identitas asli terjajah. Dengan melakukan mimikri, terjajah mengaburkan konstruksi "penjajah" yang menyematkan label minor dan berhak bertindak diskriminatif terhadap “terjajah." ${ }^{41}$ Meski paradigma poskolonial yang diusung Bhabha berangkat dari setting sosiokultur-politik India pasca penjajahan, namun paradigma ini suitable untuk diterapkan guna membaca realitas dominan dan lemah di berbagai lanskap sosial.

Konsep mimikri dan mockery Bhabha dirasa penulis relevan untuk menjelaskan bentuk-bentuk survival tactics pemuda Aboge dalam merespons tindak diskriminatif yang menimpanya, yakni dengan mempertontonkan sikap tunduk sambil melawan sembari mengonstruksi identitas baru sebagai bentuk kamuflase, sehingga penulis merasa perlu menghadirkannya dalam artikel ini sebagai alat analisis.

Strategi komunitas "terjajah" melawan "penjajah" yang ditawarkan Bhabha bukanlah satusatunya perspektif dalam membaca kecerdikan subordinat melawan konstruksi wacana ordinat terhadapnya. Dalam perspektif subaltern studies, James C. Scott menawarkan pemahaman atas strategi yang digunakan petani gurem di Sedaka Malaysia dalam melakukan perlawanan sehari-hari terhadap kekuatan struktural yang tidak adil padanya. Dalam ketidakadilan tuan tanah dan negara, mereka tak berdiam diri, namun melakukan perlawanan diam yang bersifat tertutup, kerap dilancarkan secara individual, dan tak terorganisir. Jika perlawanan frontal-terbuka yang dipilih kerap mendapatkan respons represif dan cepat dipadamkan negara melalui aparatnya, maka perlawanan kecil-kecilan sehari-hari ini dipilih karena nyaris tak berisiko. ${ }^{42}$

Bentuk perlawanan kecil-kecilan ini menjadikan pihak berkuasa tak dapat berbuat apa-apa dan pasrah tatkala individu-individu subordinat melakukan gerakan resistensi senyap melalui berbagai

\footnotetext{
${ }^{39}$ Bhabha, The Location of Culture, 60.

${ }^{40} \mathrm{Homi}$ Bhabha, "Of Mimicry and Man: The Ambivalence of Colonial Discourse," Discipleship: A Special Issue on Psychoanalysis 28 (1984): 127-28.

${ }^{41}$ Bhabha, "Of Mimicry and Man," 126.

${ }^{42}$ Loekman Soetrisno, "Pengantar," dalam Senjatanya Orang-orang yang Kalah: Bentuk Perlawanan Sehari-hari Kaum Petani, oleh James C. Scott (Jakarta: Yayasan Obor Indonesia, 2000), xvi-xvii.
} 
Mochammad Zaka Ardiansyah

ekspresi protes, perang kata-kata dengan menggunjing di belakang, mengikuti perintah majikan sambil "membandel," datang bekerja tanpa alat, ${ }^{43}$ sabotase, pemboikotan, pembakaran lahan, pemogokan, pencurian, menghindar, melarikan diri, ${ }^{44}$ menunda pekerjaan, penolakan penggunaan teknologi, ${ }^{45}$ memperlambat pekerjaan, pura-pura bodoh, dan pura-pura menuruti permintaan. ${ }^{46}$ Tindakan-tindakan resistensi diam ini dilakukan sang lemah sebagai respons atas berbagai ketidakadilan yang dilakukan pihak dominan, seperti tak merasakan manfaat atas program yang dihadirkan, ${ }^{47}$ gerah dengan stigma negatif yang disematkan kepadanya, penundaan upah kerja, tuntutan atas rendahnya kesejahteraan, dan sebagainya.

Meski resistensi diam yang dipaparkan Scott dalam penelitiannya di Sedaka merupakan representasi pertarungan kelas antara kaya-miskin yang dilakukan petani gurem melawan tuan tanah dan penguasa, namun pola resistensi ini relevan untuk membaca aneka taktik bertahan pemuda Aboge dalam merespons stigmatisasi, ketidakadilan, dan pemaksaan kebebasan beragama yang menimpanya, sehingga penulis juga menggunakannya untuk menganalisis data lapangan dalam kertas kerja ini. Tak lupa, penulis juga memanggil-manggil teori tindakan sosial Max Weber untuk membantu penulis mengidentifikasi ragam motif pemuda Aboge melakukan beragam survival tactics, baik dengan mimikri maupun perlawanan diam. ${ }^{48}$

\section{F. Ragam Survival Tactics Pemuda Aboge di Lembaga Pendidikan}

Alih-alih mendapatkan rekognisi dan jaminan hak beragama dan berkeyakinan, beberapa pemuda Aboge justru menerima serangkaian perlakuan intoleran dan diskriminatif di lembaga pendidikan. Lembaga pendidikan yang seharusnya menjadi ekosistem yang baik untuk belajar menghargai diversitas, tak jarang menjadi arena yang mempertontonkan model buruk pengelolaan keragaman pada siswanya. Sebagai sebuah respons atas ancaman, anjuran, dan agenda unifikasi yang dilakukan guru agama atau guru mata pelajaran keagamaan, tak jarang pemuda Aboge meresponsnya dengan mengembangkan beragam survival tactics untuk dapat tetap menjalankan keyakinan dan tradisinya, meski diam-diam.

\footnotetext{
${ }^{43}$ Soetrisno, "Pengantar," xix.

${ }^{44}$ James C. Scott, Weapons of the Weaks: Everyday Forms of Peasant Resistance (New Haven and London: Yale University Press, 1985), 241 and 246.

${ }^{45}$ Scott, Weapons of the Weaks, 247 and 251.

${ }^{46}$ Scott, Weapons of the Weaks, xvi.

${ }^{47}$ Soetrisno, "Pengantar," xx.

${ }^{48}$ Empat motif tindakan sosial yang diigunakan penulis adalah zweckrationalitat atau rasionalitas instrumental, wertrationalitat atau rasionalitas nilai, tindakan afektif, dan tindakan tradisional. Selengkapnya baca: George Ritzer dan Barry Smart, Handbook of Social Theory (London: SAGE Publications, 2003), 59.
} 
Beberapa tindak diskriminatif yang pernah dirasakan pemuda Aboge di lembaga pendidikan ${ }^{49}$ membuat mereka kerap memosisikan dirinya dalam posisi yang ambivalen, di satu sisi harus menunjukkan diri mengikuti perintah dan menuruti ancaman gurunya untuk meninggalkan Aboge, di sisi lain berusaha mempertahankan keyakinannya. Singkatnya tak jarang mereka melakukan mimikri dan resistensi diam sebagai bentuk survival tactics. Bentuknya sangat beragam dan sangat tergantung pada situasi, seberapa besar ancaman, dan potensi risiko yang mereka terima. Sebagai respons atas stimulus eksternal yang mereka terima, maka pilihan survival tactics yang diambil oleh pemuda Aboge sangat personal dan unik.

\section{a. Penyamaran Sempurna di Kampus Muhammadiyah}

Sebagai sebuah respons atas tindak diskriminatif yang menjadi stimulus, survival tactics berjalan berdasarkan prinsip sebab-akibat. Berbagai taktik bertahan yang dilakukan pemuda Aboge terjadi karena beberapa hal, pertama sebagai respons atas serangkaian tindakan diskriminatif yang menimpanya, kedua, sebagai pencegahan agar tindakan diskriminatif, labeling, dan alienasi tak menimpanya.

Fauzi Amin, ${ }^{50}$ pemuda Aboge yang belajar di sebuah kampus Muhammadiyah di Probolinggo selalu melakukan penyamaran sebagai pemuda NU di ruang privat kelas untuk mencegah perundungan yang selalu dikhawatirkannya datang dari dosennya. Pada dosennya di kampus Muhammadiyah, Fauzi mengaku sebagai pemuda NU karena tak ingin dosen dan temantemannya tahu bahwa dirinya adalah pemuda Aboge. la tak ingin seisi kelas heboh mempertanyakan alasannya mengikuti Aboge dan mengkhawatirkan dirinya bakal terisolir. "lya, bisa jadi sekian temen mahasiswa saya: "jangan, itu Aboge" kan gitu kan mas? ya lebih baik jawab NU kalo memang ditanya," tuturnya.

Sementara di ruang publik kampung tempat tinggalnya, Desa Kendang Kempul, setiap Idul Fitri dan Idul Adha, dirinya harus diam-diam mengikuti Salat Id dua kali. Hari pertama dirinya mengikuti Salat Id bersama masyarakat Kendang Kempul yang mayoritas bertradisi NU untuk mengukuhkan diri bahwa dirinya tak lagi mengikuti Aboge. Keesokan harinya, la kembali Salat Id bersama komunitas Aboge Desa Bendo di Langger ${ }^{51}$ sang guru, Bidereh Zul, untuk mengukuhkan di hadapan sang guru bahwa dirinya masih setia mengikuti tradisi sang guru yang Aboge. Namun, di hadapan orang yang baru dikenalnya, selain teman kuliah dan pemuda kampungnya, ia bakal mengaku sebagai Aboge. Hal ini dilakukan karena ia khawatir mendapatkan pertanyaan spesifik

\footnotetext{
${ }^{49}$ Ragam tindak diskriminatif yang menimpa pemuda Aboge di sekolah dapat dibaca di Ardiansyah, "School, Symbolic Violence, and Religious Experience of Aboge Youth."

${ }^{50}$ Selanjutnya penulis sebut Fauzi

${ }^{51}$ Langger adalah tempat salat atau Musala dalam bahasa Madura
} 
tentang ragam ajaran NU yang tak dipahaminya dengan baik. la mengaku, khawatir "mati kutu" karena tak dapat menjawab pertanyaan-pertanyaan teknis terkait NU. ${ }^{52}$

Keputusan menyamar sebagai pengikut NU diambilnya lantaran teman-temannya yang kuliah di tempat yang sama banyak berasal dari tradisi NU sehingga dengan melakukan itu, ia merasa tak sendiri. la mengalkulasi, dengan mengaku sebagai pengikut NU akan membuatnya terbebas dari risiko perundungan. Jika dirinya berterus terang sebagai pengikut Aboge, ia khawatir mendapat stigma negatif dan dijauhi teman-temannya "dampaknya itu kan mas, bisa besar itu", tambahnya. Motivasi yang menjadikan Fauzi menyamar di kelas adalah karena dia menakar risiko tindak diskriminatif yang dapat ia terima di kampus Islam. la tak yakin, dosen dan teman-temannya sesama mahasiswa dapat menerima dirinya sebagai Aboge. "Ya kalo di kampus Islam....yang rawan kan itu mas, kalo di umum ya nggak seberapa khawatir", tuturnya. ${ }^{53}$ Posisi Fauzi sebagai minoritas membuatnya harus senantiasa menutup dan mengingkari identitasnya, daripada bersuara lantang namun tak mendapatkan rekognisi.

\section{b. Penyamaran di Pesantren dan Sekolah Islam}

Pengalaman beragama Fauzi juga dirasakan Budiarti, pemuda Aboge Desa Sindang Kerto dan Abdul Karim, ${ }^{54}$ pemuda Kendang Kempul, selama menjadi siswa Sekolah Menengah Atas Murni Abadi. Di tahun pertama belajar di pesantren, mula-mula Budiarti berpuasa bersama dengan warga pesantren yang berafiliasi ke NU, singkatnya sehari lebih cepat dari keluarganya yang meyakini perhitungan Aboge.

Budiarti baru menyadari bahwa dia memulai puasa terlalu cepat dan berbeda dengan puasa komunitas Aboge tatkala dirinya merayakan Idul Fitri di kampungnya yang dilaksanakan selisih sehari setelah pesantrennya. Setelah mengetahui bahwa keluarganya dan komunitas Aboge Desa Sindang Kerto memulai puasa Ramadan lebih lambat dibandingkan jadwal puasa yang diikuti pesantrennya, di tahun kedua dan ketiga di pesantren, Budiarti harus menyamar sebagai perempuan yang sedang menstruasi guna menyembunyikan kenyataan bahwa dirinya belum mulai berpuasa Ramadan seperti santri pesantren lainnya. Kebohongan ini dilakukannya untuk dapat konsisten mengawali puasa Ramadan bersama keluarganya, sesuai keyakinan terhadap perhitungan Aboge yang dipegang keluarganya turun-temurun. ${ }^{55}$

Penyamaran ini dilakukan tatkala seluruh santri melakukan puasa Ramadan hari pertama, sementara berdasarkan sistem Aboge la meyakini bahwa awal Ramadan baru tiba keesokan

\footnotetext{
${ }^{52}$ Amin, Wawancara dengan Fauzi Amin, seorang pemuda Aboge dari Desa Kendang Kempul, Kecamatan Karang Lo, Probolinggo.

${ }^{53}$ Amin, Wawancara.

${ }^{54}$ Selanjutnya penulis sebut Karim

${ }^{55}$ Budiarti, Wawancara dengan Budiarti, seorang pemuda Aboge dari Desa Sindang Kerto, Kecamatan Umpak Palu, Lumajang, Desember 2018.
} 
harinya. Singkatnya, saat di hari pertama santri pesantren telah mulai berpuasa Ramadan, dirinya meyakini hari tersebut belum saatnya berpuasa Ramadan. Hari pertama Ramadan di pesantren menjadi hari yang menyulitkan kehidupan Budiarti karena dia harus berpura-pura tak menjalankan puasa dengan dalih menstruasi namun harus melaksanakan salat dengan sembunyi-sembunyi ${ }^{56}$ agar penyamarannya tak terbongkar. la mengaku harus pintar "mengecoh" teman-temannya agar tak tertangkap basah bahwa dirinya belum berpuasa Ramadan. Menurutnya, teman-temannya tak akan bertanya jika ia melakukan penyamaran dengan baik. "Kan mereka nggak mungkin nanya, kenapa nggak puasa, gitu, kalo kita sendiri bisa.. ..mengecoh mereka lah.. ...harus pinter menyembunyikan", ujarnya. ${ }^{57}$

Meski tak sambil mengolok dalam diam, penyamaran Budiarti sebagai wanita menstruasi dilakukan guna beradaptasi dengan keputusan pesantren untuk berpuasa sesuai hasil sidang Isbat. Sebagai santri yang seharusnya taat pada tindak-tanduk Kiai, posisinya ambivalen, di satu sisi dirinya harus mengesankan diri patuh dengan berpura-pura puasa, di sisi lain kepatuhan ini tak lebih dari kepatuhan artifisial karena berusaha mempertahankan keyakinannya dan ketaatan pada perhitungan Aboge sehingga ia baru betul-betul memulai puasa Ramadan keesokan harinya.

Budiarti menyaksikan, dalam sebuah pengajian bandongan di pesantren, Kiai Yanuar, pengasuh pesantrennya, mempertanyakan alasan beberapa santri memulai puasa Ramadan berdasarkan sistem perhitungan kalender Aboge. Kiainya mempertanyakan pada temannya sesama Aboge "kenapa masih ikut yang belakang, tidak ikut yang depan saja?" ujarnya. Di luar sesi belajar pun, santri ini juga kembali ditanya oleh teman-temannya sesama santri. Melihat realitas ini, Budiarti merasa bersyukur bahwa dirinya tidak sendiri, "oh.. ada temennya saya" paparnya sambil tertawa. Meski mengelabui teman-temannya di pesantren, Budiarti mengaku tidak tahu apa itu Aboge dan bagaimana sistem perhitungannya tatkala ditanya penulis. Menurutnya, alasannya ikut karena "meskipun saya ikut yang Aboge tapi belum memahami Aboge itu apa, saya juga belum mengerti secara luas tentang Aboge itu apa, saya ngikut aja, ngikut orang tua aja gitu." 58

Tampak bahwa motif dirinya mengikuti Aboge dilakukan karena melanggengkan tradisi, tindakan ini dilakukan untuk mempertahankan keyakinan yang dipegang oleh orang tuanya dan diajarkan secara langsung oleh sang kakek kepadanya. Motif Budiarti melakukan ini tak berbeda dengan tindakan tradisional Weber. ${ }^{59}$

\footnotetext{
${ }^{56}$ Santri pesantren meyakini bahwa menstruasi menggugurkan kewajiban puasa Ramadan dan salat bagi perempuan.

${ }^{57}$ Budiarti, Wawancara dengan Budiarti, seorang pemuda Aboge dari Desa Sindang Kerto, Kecamatan Umpak Palu, Lumajang.

${ }^{58}$ Budiarti, Wawancara.

${ }^{59}$ Ritzer dan Smart, Handbook of Social Theory, 59.
} 
Penyamaran lain dilakukan Karim, pemuda Kendang Kempul, selama menjadi siswa Sekolah Menengah Atas Murni Abadi. la mengalami pengalaman diskriminatif dari beberapa oknum guru dan teman-teman sekolahnya karena mereka menerimanya sebagai pengikut Aboge. Selain mendapat pertanyaan-pertanyaan diskriminatif, dirinya pernah mendapatkan hukuman bekerja bakti membersihkan sekolah karena ketahuan sang guru bahwa dirinya masih mengikuti Aboge. Karim tak jarang mendapatkan anjuran untuk meninggalkan Aboge dari gurunya secara terbuka. ${ }^{60}$ Demi menjaga keyakinannya--mengingat tak memungkinkan melakukan penolakan terbuka-- ia berusaha tampak taat pada anjuran sang guru, meski di balik ketaatan itu, la melakukan perlawanan diam dengan melakukan tipu muslihat kepada sang guru sebagai taktik bertahan dirinya sebagai minoritas marginal.

Tatkala masih bersekolah di SMA Murni Abadi, di malam menjelang hari pertama puasa Ramadan, Karim mengikuti ibadah-ibadah sunah seperti salat tarawih dan tadarus bersama siswa lain di sekolah untuk "mengesankan" pada sang guru "seolah-olah" keesokan harinya dia akan melaksanakan puasa bersama Muslim arus utama. ${ }^{61}$

\section{G. Survival Tactics Pemuda Aboge: Sebuah Analisis}

Dalam merespons potensi dan realitas diskriminatif di lembaga pendidikan para pemuda Aboge mengembangkan beragam taktik bertahan. Survival tactics yang mereka lakukan adalah bagian dari fleksibilitas identitas yang niscaya dilakukan individu dari kelompok minoritas “terjajah." Pengalaman mengembangkan respons terhadap kondisi tak menguntungkan di lembaga pendidikan dilakukan Fauzi dan Karim, pemuda Aboge Desa Kendang Kempul, Kecamatan Karang Lo, Probolinggo serta Budiarti, pemuda Aboge dari Desa Sindang Kerto, Kecamatan Umpak Palu Lumajang.

Fauzi memutuskan melakukan mimikri ${ }^{62}$ di Kampus Muhammadiyah karena motif rasionalitas instrumental. ${ }^{63}$ Pertimbangannya, penyamaran sebagai NU adalah pilihan yang paling praktis karena dirinya lebih aman sebagai minoritas. Ia menilai NU adalah komunitas dengan populasi besar, sehingga membuatnya merasa menjadi bagian dari komunitas besar. Berbeda, di luar kampus, di hadapan orang yang baru dikenalnya, Fauzi nyaman menyebut dirinya sebagai Aboge karena sikap takzim pada Bidereh Zul, guru mengajinya di masa kanak-kanak yang menjadi tokoh Aboge Desa Bendo, Kecamatan Budi Joyo, Probolinggo. ${ }^{64}$

\footnotetext{
${ }^{60} \mathrm{Abdul}$ Karim, Wawancara dengan Abdul Karim, seorang pemuda Aboge Desa Kendang Kempul, Kecamatan Karang Lo, Probolinggo, Desember 2018.

${ }^{61}$ Karim, Wawancara.

${ }^{62}$ Bhabha, The Location of Culture, 86-87.

${ }^{63}$ Stephen Kalberg, ed., Max Weber: Readings and Commentary on Modernity (Malden: Blackwell Publishing, 2005$), 36$.

${ }^{64}$ Identitas kedua ini dibangun atas pertimbangan rasionalitas nilai/wertrationalitat Weber, sebagaimana penulis tulis dalam Ardiansyah, "School, Symbolic Violence, and Religious Experience of Aboge Youth," 65.
} 
Meski belajar di lembaga pendidikan Muhammadiyah yang memiliki beberapa perbedaan -misal sistem hukum Islam, teologi, dan tradisi keagamaan-- dengan NU, dirinya merasa lebih aman tatkala menjelma sebagai NU. Dengan membangun identitas barunya sebagai pemuda NU, Fauzi mengonstruksi ruang budaya ketiga yang berbeda dengan Muhammadiyah dan Aboge. Muhammadiyah adalah representasi budaya dominan di kampusnya dan Muslim Aboge sebagai identitas aslinya karena dirinya mengkreasikan "ruang identitas baru," yakni NU.

Pilihannya menyamar dalam identitas pemuda NU --bukan sang dominan, Muhammadiyah-menjadi pola penyamaran yang berbeda sama sekali dengan yang digambarkan Bhabha dalam lanskap sosio-historis poskolonial. Jika Bhabha menggambarkan subyek terjajah-subordinat kerap meminjam identitas ordinat-dominan dengan melakukan mimikri sambil mengolok (mockery), maka Fauzi meminjam identitas NU, untuk berlindung dari potensi perundungan dan labeling yang dikawatirkannya akan dilakukan oleh dosen dan teman-temannya di kampus Muhammadiyah.

Meski ambivalen, Fauzi dapat dengan mudah mengganti identitasnya berdasarkan kadar tantangan yang dihadapinya. Semakin fungsional-ekuilibrium komunitas yang dihadapinya, ia dapat semakin terbuka dengan identitasnya, Aboge. Begitu pun sebaliknya, ia akan dengan mudah melakukan penyamaran tatkala menemui komunitas yang diprediksinya bakal mengancamnya.

Pengalaman Fauzi berbeda dengan yang dialami Budiarti dan Karim. Tatkala belajar di pesantren yang berafiliasi NU, tak jauh dari pusat Kota Lumajang, la memutuskan berkamuflase. Keputusannya melakukan mimikri menempatkannya dalam in-between space, ruang antara baru yang ditempati terjajah yang menurut Bhabha terdapat antara ruang penjajah dan terjajah. ${ }^{65}$ Keputusannya berpurapura menstruasi dan diam-diam melaksanakan salat merupakan bentuk tindakan --meminjam istilah Weber-- berbasis rasionalitas nilai (value-rationality), ${ }^{66}$ yakni dilakukan semata-mata untuk melaksanakan nilai yang dipegang teguh dan diturunkan dari nenek moyangnya.

Pengalaman Budiarti juga serupa dengan pengalaman Karim merespons ajakan beberapa gurunya di SMA Murni Abadi untuk meninggalkan Aboge. Saat masih belajar di sekolah yang bernaung di yayasan yang berafiliasi ke NU ini la mengaku pernah di hukum hanya gara-gara masih mengikuti Aboge ini berpura-pura melaksanakan salat tarawih dan bertadarus di sekolah pada malam 1 Ramadan versi pemerintah. Padahal ia harusnya baru melaksanakan tarawih pertama esok harinya.

Strategi Karim menjalankan ibadah sunah tarawih dan tadarus untuk mengesankan pada sang guru bahwa dirinya besok "telah berpuasa" merupakan strategi Karim agar dirinya dapat mempertahankan keyakinannya untuk memulai puasa Ramadan berdasarkan perhitungan Aboge sekaligus menghindarkan potensi hukuman dari sang guru pada siswa-siswa Aboge yang

\footnotetext{
${ }^{65}$ Bhabha, "Of Mimicry and Man: The Ambivalence of Colonial Discourse," 126-27.

${ }^{66}$ Ritzer dan Smart, Handbook of Social Theory, 59.
} 
Mochammad Zaka Ardiansyah

"membangkang." Tindakan ini hanyalah taktiknya untuk memperjuangkan keyakinannya tanpa harus membuat sang guru berang dengan berpura-pura mengikuti perintahnya, padahal tak lebih dari tindakan menyenangkan sang guru -untuk tidak mengatakan mengerjai. Survival tactics dengan mengambil bentuk perlawanan kecil-kecilan dengan berpura-pura ini lebih efektif dan minim risiko daripada mengembangkan konfrontasi terbuka. ${ }^{67}$

Sebagai strategi penyamaran yang dipilih kalkulasi risiko, maka motifnya bisa dengan mudah ditebak, berdasarkan pertimbangan rasionalitas instrumental ${ }^{68}$ dan tentu saja pelaksanaan ibadah sunah khas Ramadan ini tak serta-merta membuat Karim telah memulai puasa Ramadan lebih awal bersama dengan sang guru dan warga sekolah lain. Karim tak benar-benar melakukan puasa keesokan harinya.

Budiarti dan Karim meminjam identitas NU yang digunakan lembaga pendidikan untuk mengesankan dirinya NU, meski diam-diam mempertahankan identitasnya sebagai Aboge dengan cara tetap mengikuti Salat Idul Fitri bersama keluarga dan komunitas Aboge di desanya, sehari lebih lambat dari pelaksanaan di pesantren dan sekolahnya. Keduanya mengambil ruang antara atau ruang ketiga dengan meminjam identitas dominan yang diusung lembaga pendidikannya, yakni NU, sambil diamdiam mempertahankan identitas Aboge.

\section{H. Penutup}

Tanpa berusaha menyimpulkan, dalam bagian akhir kertas kerja ini, penulis menggarisbawahi bahwa dalam merespons diskriminasi yang menimpanya, pemuda Aboge mengembangkan taktik bertahan (survival tactics) dengan mimikri dan melakukan perlawanan diam yang bentuknya sangat subyektif dan berubah-ubah. Dari artikel ini, penulis menemukan bentuk baru mimikri yang dilakukan pemuda Aboge yang berbeda dengan pola mimikri Homi K. Bhabha yang ditawarkannya dalam studi poskolonial, karena dalam melakukan penyamaran di kampus Muhammadiyah, pemuda Aboge tidak menggunakan identitas Muhammadiyah sebagai identitas dominan, namun meminjam identitas komunitas lain, yakni NU.

Bentuk mimikri ini tak menjadikan batas konstruksi dominan-subordinat menjadi kabur, namun justru membuat varian baru mimikri yang dilakukan subyek subordinat, yakni mimikri yang tak menempati in-between space karena subyek subordinat menciptakan ruang baru dengan mengonstruksi identitas lain secara artifisial, yakni menjelma sebagai NU.

\footnotetext{
${ }^{67}$ Pura-pura mengerjakan permintaan sang guru untuk menciptakan kesan patuh padahal sesungguhnya tidak merupakan tindakan ala petani Sedaka versus tuan tanah sebagaimana digambarkan Scott. Scott, Weapons of the Weaks: Everyday Forms of Peasant Resistance, xvi.

${ }^{68}$ Ritzer dan Smart, Handbook of Social Theory, 59.
} 


\section{Referensi}

Amin, Fauzi. Wawancara dengan Fauzi Amin, seorang pemuda Aboge dari Desa Kendang Kempul, Kecamatan Karang Lo, Probolinggo, Desember 2018.

Ardiansyah, Mochammad Zaka. "School, Symbolic Violence, and Religious Experience of Aboge Youth." Didaktika Religia Vol. 8, no. 1 (2020).

Arif, Bustanul. Wawancara dengan Kiai Bustanul Arif, Desa Kombong, Kecamatan Budi Joyo, Probolinggo, 23 Januari 2018.

Bagir, Zainal Abidin, dan Samsul Maarif. "Pengantar." Dalam Pasang Surut Rekognisi Agama Leluhur dalam Politik Agama di Indonesia. Yogyakarta: CRCS, 2018.

Bhabha, Homi. "Of Mimicry and Man: The Ambivalence of Colonial Discourse." Discipleship: A Special Issue on Psychoanalysis 28 (1984).

Bhabha, Homi K. The Location of Culture. London: Routledge, 1994.

Bruinessen, Martin van. "Global and Local in Indonesian Islam." Southeast Asian Studies 37, no. 2 (September 1999).

- - - Tarekat Naqsyabandiyah di Indonesia. Bandung: Mizan, 1992.

Budiarti. Wawancara dengan Budiarti, seorang pemuda Aboge dari Desa Sindang Kerto, Kecamatan Umpak Palu, Lumajang, Desember 2018.

Farikhatin, Anis. "Berhadapan dengan Prasangka: Merespons Isu Sesat Ahmadiyah terhadap Sekolah PIRI I Yogyakarta." Dalam Mengelola Keragaman di Sekolah: Gagasan dan Pengalaman Guru, disunting oleh Suhadi, Linah Khairiyah Pary, Fardan Mahmudatul Imamah, dan Marthen Tahun. Yogyakarta: CRCS, 2016.

Geertz, Clifford. The Religion of Java. Chicago: The University of Chicago Press, 1976.

Harsun. Wawancara dengan Kiai Harsun, seorang Tokoh Aboge di Desa Karangsari, Kecamatan Rowosari, Lumajang, 16 November 2017.

Jakarta, Tim PPIM UIN Syarif Hidayatullah. Api dalam Sekam: Keberagamaan Muslim Gen-Z; Survei Nasional tentang Keberagamaan di Sekolah dan Universitas di Indonesia. Tangerang Selatan: PPIM UIN Jakarta dan UNDP Indonesia, 2018.

Kalberg, Stephen, ed. Max Weber: Readings and Commentary on Modernity. Malden: Blackwell Publishing, 2005.

Karim, Abdul. Wawancara dengan Abdul Karim, seorang pemuda Aboge Desa Kendang Kempul, Kecamatan Karang Lo, Probolinggo, Desember 2018.

Muamar. Wawancara dengan Kiai Muamar, seorang tokoh Aboge Desa Karang Lo, Kecamatan Karang, Probolinggo, Agustus 2016.

- - - Wawancara dengan Kiai Muamar, seorang tokoh Aboge Desa Karang Lo, Kecamatan Karang, Probolinggo, 23 Januari 2018.

Nasiri. Wawancara dengan Kiai Nasiri, seorang Tokoh Aboge Dusun Kertas, Desa Dolo, Kecamatan Puntodewo, Jombang, 25 November 2017.

Prabowo, A., M. Mamat, Sukono, dan Ngadiman. "Carrying Javanese Local Wisdom in Mathematical Model." Journal of Physics: Conference Series 1179 (Juli 2019): 012005.

Prawiro, Abdurrahman Misno Bambang. "Islam Aboge: Islam and Cultural Java Dialogue (A Study of Islam Aboge Communities in Ujungmanik, Cilacap, Central Java, Indonesia)." International Journal of Nusantara Islam 1, no. 2 (2013).

Qurtuby, Sumanto Al. "Reconciliation from Below: Indonesia's Religious Conflict and Grassroots Agency for Peace." Peace Research 44/45, no. 2/1 (2013 2012).

Rachmadhani, Arnis. "Role of Wali, Ancient Mosque and Sacred Tomb in Islam Spreading Dynamics in Cikakak." IBDA': Jurnal Kajian Islam dan Budaya 14, no. 2 (Desember 2016).

Rambe, Safrizal. Peletak Dasar Tradisi Berpolitik NU Sang Penggerak Nahdlatul Ulama KH. Abdul Wahab Chasbullah Sebuah Biografi. Jakarta: Madani Institute, 2020.

Redfield, Robert. Peasant Society and Culture: An Anthropological Approach to Civilization. Chicago: The University of Chicago Press, 1956.

Ritzer, George, dan Barry Smart. Handbook of Social Theory. London: SAGE Publications, 2003.

Sakirman. "Islam Aboge dalam Tradisi Jawa Alastua." Ibda': Jurnal Kebudayaan Islam 14, no. 2 (Juli 2016 ). 
Scott, James C. Weapons of the Weaks: Everyday Forms of Peasant Resistance. New Haven and London: Yale University Press, 1985.

Sekretariat Negara RI. Undang-undang Nomor 20 Tahun 2003 tentang Sistem Pendidikan Nasional (2003).

Soejono, Djoko, Agus Supriono, dan Julian Adam Ridjal. "Faktor Pendorong Dan Penghambat Mewujudkan Model Sinergis Pengembangan Wilayah Tapal Kuda Menjadi Kesatuan Daerah Perencanaan Di Era Otonomi Daerah." JSEP (Journal of Social and Agricultural Economics) Vol. 5, no. 1 (2011).

Soetrisno, Loekman. "Pengantar." Dalam Senjatanya Orang-orang yang Kalah: Bentuk Perlawanan Seharihari Kaum Petani, oleh James C. Scott. Jakarta: Yayasan Obor Indonesia, 2000.

Sulaiman. "Islam Aboge; Pelestarian Nilai-nilai Lama di Tengah Perubahan Sosial." Analisa: Journal of Social Science and Religion 20, no. 1 (2013).

Syahrin, Muhammad Alfi, Turmudi, dan Entit Puspita. "Study Ethnomathematics of Aboge (Alif, Rebo, Wage) Calendar as Determinant of the Great Days of Islam and Traditional Ceremony in Cirebon Kasepuhan Palace." Dalam Proceedings of International Seminar on Mathematics, Science, and Computer Science Education (MSCEIS 2015). AIP Publishing, 2016.

Syaukani, Ahmad. Wawancara dengan Kiai Ahmad Syaukani, seorang Tokoh Aboge di Desa Podang, Kecamatan Karang Lo, Probolinggo, Agustus 2016.

“Undang-undang Dasar Negara Republik Indonesia Tahun 1945," 1945.

Undang-undang Republik Indonesia Nomor 35 Tahun 2014 tentang Perubahan atas Undang-undang Nomor 23 Tahun 2002 tentang Perlindungan Anak (2014).

Wahid, Yenny Zannuba, Mujtaba Hamdi, Aniq HT, Libasut Taqwa, dan Nurun Nisa. "Laporan Tahunan Kemerdekaan Beragama/Berkeyakinan (KBB) Tahun 2019 di Indonesia: Kemajuan Tanpa Penyelesaian Akar Masalah." Jakarta: Wahid Foundation, 2020.

Wibisono, Bambang, dan Akhmad Haryono. Komunikasi Antar Budaya di Tapal Kuda: Antisipasi Konflik dalam Keluarga. Yogyakarta: Deepublish, 2020.

Widyandini, Wita, Yohana Nursruwening, dan Basuki. "Penerapan Konsep Dasar Pemukiman Aboge Cikakak pada Pemukiman Aboge Cibangkong di Kabupaten Banyumas." Purwokerto: Universitas Muhammadiyah Purwokerto, 2015.

Zulfikar. Wawancara dengan Bindereh Zul, seorang Tokoh Aboge Desa Bendo, Kecamatan Budi Joyo, Pobolinggo, Desember 2018. 